\title{
Fuelwood consumption, restrictions about resource availability and public policies: impacts on the French forest sector
}

\author{
Sylvain CAURLA
}

Philippe DELACOTE

Franck LECOCQ

Ahmed BARKAOUI

Août 2009

Document de travail

$n^{\circ}$ 2009-03 


\title{
Fuelwood consumption, restrictions about resource availability and public policies: impacts on the French forest sector*
}

\author{
Sylvain CAURLA ${ }^{1,2}$ \\ Philippe DELACOTE ${ }^{2,1}$ \\ Franck LECOCQ ${ }^{1,2}$ \\ Ahmed BARKAOUI ${ }^{2,1}$
}

Août 2009

Document de travail du LEF $n^{\circ} \mathbf{2 0 0 9 - 0 3}$

\begin{abstract}
Résumé
Consommation de bois-énergie, disponibilité de la ressource forestière et politiques publiques: impacts sur la filière forêt-bois française

Dans le contexte actuel de changement climatique et d'augmentation des prix de l'énergie, la part de bois énergie dans la consommation d'énergie primaire pourrait augmenter, notamment dans les pays où la ressource forestière est abondante. Toutefois, une augmentation de la consommation de bois-énergie pourrait entrainer des impacts non négligeables pour la filière forêt-bois. Cet article propose d'évaluer ces impacts pour la France en utilisant un nouveau modèle du secteur forestier français et en comparant quatre politiques entrainant l'augmentation de la consommation de bois énergie. Tout d'abord, il apparaît que les résultats diffèrent grandement suivant que les politiques touchent l'amont de la filière ( le producteur) ou l'aval (le consommateur) avec un arbitrage entre la balance commerciale et l'intensité de récolte. Les résultats font ensuite apparaître qu'une augmentation même modeste de la consommation de bois énergie se traduit par une tension visible sur le stock sous des hypothèses de disponibilité de la ressource pessimistes.
\end{abstract}

Mots clés : modélisation du secteur forestier, bois-énergie, biomasse-énergie, politiques publiques .

\begin{abstract}
In the context of climate change and of increasing energy prices, the share of fuelwood in primary energy consumption may increase, especially in countries with large forest endowments. However, larger fuelwood consumption may have non-negligible impacts on forest sectors. This paper assesses those impacts for France using a new model of the French forest sector, and comparing four different policy options to boost fuelwood demand. First, supply- and demand-side policies yield very different outcomes, with a trade-off between trade balance and harvest intensity. Second, even a modest increase in fuelwood consumption leads to tensions over forest stock over time under pessimistic views about resource availability.
\end{abstract}

Key words : forest sector modeling, fuelwood, bioenergy, public incentives.

Classification JEL : Q23, Q28.

\footnotetext{
* An earlier version of this paper was presented at the 2009 International Energy Workshop (Venice, Italy). We acknowledge useful comments and insights from the participants.

${ }^{1}$ AgroParisTech, Engref, Laboratoire d' Economie Forestière, F-54000 Nancy, France

${ }^{2}$ INRA, UMR356 Economie Forestière, F-54000 Nancy, France
} 


\section{Introduction}

As part of its climate change and energy package, the European Union aims at increasing the share of renewable in its overall energy mix to $20 \%$ by 2020 . Biomass energy is expected to play a major role in meeting this objective, most notably in countries such as France, where timber resources are both abundant (France has the fourth largest forest cover among EU25 countries) and under-harvested, in the sense that only an estimated $60 \%$ of the total annual increment in wood resources is harvested, leaving room for an additional annual harvest of some 30 to $40 \mathrm{Mm} 3$ without decreasing total stock (IFN, 2008).

On this basis, French forest sector development plans call for an increase in timber and fuelwood consumption, and the Government has encouraged the construction of new mediumto large-scale combined heat and power biomass plants. Yet there is considerable uncertainty as to how much of this physical volume is in fact commercially available. High exploitation costs in mountain areas make part of this stock commercially unattractive anyway. In addition, more than one third of French forest properties are below 25ha, and small-scale forest owners do not necessarily react to price signals as large-scale forest owners do. Thus, concerns have also been raised that an increase in fuelwood consumption might actually restrict supply of raw material for other parts of the French forestry sector, notably for the pulpwood industry (Chasset, 2007).

The objective of this paper is to assess the economic implications of an increase in biomass energy demand on the French forest sector, in a context of uncertainty about the commercially available stock of timber. To do so, we develop a partial equilibrium model of the French forest sector, and examine how it reacts to a gradual increase in fuelwood demand from now on to 2020, under various assumptions about commercially available stock.

Four potential public policies to boost fuelwood consumption are considered. First, we model an exogenous increase in demand, which mimics the current policy of encouraging medium- to large-scale biomass energy plant development. In this case the Government guarantees an additional fuelwood consumption. It can be done either by guaranteeing a given amount of public purchase on the market (fixed-demand contracts) or by entering into contracts with domestic suppliers (fixed-supply contracts). We also consider two alternatives to reach the same total increase in demand: a consumer and a producer subsidy. 
For each policy, we assess raw materials price dynamics and potential tensions between fuelwood and pulpwood. On the consumer side, we assess how increases in public demand influence market prices and private demand. We also look closely at the implications of the various policies for imports and exports, which play a significant role in assessing whether increases in the demand for fuelwood can be met while preserving sustainable management of the French forest. Section 2 describes the model. Section 3 presents simulation results, and Section 4 concludes.

\section{A Model of the French Forest Sector}

There exist several partial equilibrium models of the international forest sector, such as the Global Forest Sector Model (Buongiorno et al. 2003) or the EFI-GTM (Kallio et al. 2004). These models, however, have a very aggregate representation of individual countries such as France. In addition, these models either do not have a detailed representation of forest dynamics, or are based on monospecific, even-aged forests, which are not as dominant in France as they are in other countries. It is thus useful to develop a model that be more detailed, and that be specific to French forest conditions.

\subsection{Specific Features of the French Forest Sector}

First, most existing forest sector models only consider even-aged monospecies forests. Yet a larger variety of forest management must be considered in the French case. Uneven-aged forests are indeed an important forest management practice. Moreover coppices and coppices under standard are also frequently used. Those practices have an impact both on the growth dynamics of the forest stock and on the behavior of the forest owners. Basically, uneven-aged forests imply no clear-cutting of the forests stands, and selected harvest. Timber supply is thus potentially affected. Moreover, a large variety of timber species with different quality, growth and management patterns are to be distinguished.

Second, the French forest is characterized by over-capitalization. Indeed the state of the French forests is not consistent with industrial long-term management. Basically, French forests are considered to be under-harvested (Ballu et al., 2007). An intuitive explanation for this fact is that many forest owners do not behave as industrial forest owners and respond 
to other incentives than prices and costs. Another potential cause of under-harvesting is the important extraction costs of timber in certain regions. If prices do not match those extraction costs, it may be rational not to supply timber since timber harvesting is simply not profitable.

\section{$2.2 \quad$ A sectorial bio-economic model}

We consider a simulation model, with a succession of identical periods. Equilibria are computed sequentially, one period after another, and periods are linked by key dynamic equations, such as timber growth, and supply and demand evolution.

Our model is composed of two inter-related parts. Dynamics of the forest stock is contained in a biological module which forms the backbone of the model. This biological module is linked to an economical module through the inventory volume and the price of raw materials. The economic module describes the French forest sector dynamics with a static simulation mechanism, in a partial equilibrium framework.

\subsection{Biological forest dynamics}

Growth of timber stocks is evaluated taking into account different potential influencing factors. We distinguish: diameter classes $d$, type of management $m$, property rights $p r$, national regions $i$ and species $s$. In this sense, we are able to cope with the large variety of the French forests.

Basically, timber growth dynamics are defined as follows :

$$
F_{d, m, p r, i, s, t}=F_{d, m, p r, i, s, t-1}\left(1+r_{d, m, i, s}-d_{d, m, p r, i, s}-h_{d, m, p r, i, s}\right)
$$

$F$ represents the forest stock potentially considered for harvesting by timber suppliers. It differs from the total forest stock, in the sense that some forest land is not harvestable - because of, e.g., restrictions on logging in protected areas - and that some forest owners do not react to economic signals - e.g., non-industrial forest owners who may not be aware of the opportunities on the forest products markets. $F$ depends on the stock one period before, plus the natural increment $r$, minus natural mortality $d$ and harvest rate $h$. Rates of increment are computed based on local data of different species increment in different 
regions and under different types of management (REFERENCE). They are computed for all diameter classes.

We divide our forest stock in two components based on log diameter and type of forest management. In high forests or mixed stands, logs under $40 \mathrm{~cm}$ of diameter are preferentially used for fuelwood or pulpwood (thinnings), whereas logs over $40 \mathrm{~cm}$ are sold for lumber.In coppices, all the wood under $60 \mathrm{~cm}$ is used for fuelwood and pulpwood.

\subsection{Economic interactions}

The economic part models the whole sector, from timber suppliers to final consumers. Specification for the supply and demand functions is quite close to the one of GFPM (Buongiorno et al., 2003). Forest owners supply timber $w$ which is transformed by the timber processing industry. Processed goods $p$ are sold to final consumers. Our main theoretical contribution concerns foreign trade.

Trade: First, consistently with the GFPM, inter-regional trade (e.g. among national regions) is considered through Samuelson theory (1952): trade between regions is only determined by relative prices and transport costs. Trades between region $i$ and $j$ are noted $e_{i, j, p, t}$ and $e_{i, j, w, t}$. Transport costs are $C_{i, j, p}$ and $C_{i, j, w}, p$ refers to final products, $w$ to primary ones and $t$ to time.

Second, we consider a small open economy in which the French forest sector does not impact on international prices. Following Armington (1969), international and domestic goods are considered to be imperfect substitutes in consumption. Armington theory proceeds sequentially. First, consumers $D$ determine their demand considering a composite price $\tilde{P}_{D, i, v, t}$ of $\operatorname{good} p$ :

$$
\tilde{P}_{D, i, p, t}=\left[P_{i, p, t}^{1-\phi_{D, i, p}}\left(1-b_{D, i, p}\right)^{\phi_{D, i, p}}+P *_{p, t}^{1-\phi_{D, i, p}} b_{D, i, p}^{\phi_{D, i, p}}\right]^{1-\frac{1}{\phi_{D, i, p}}}
$$

with $P_{i, p, t}$ the local price of good $p$ and $P *_{i, p, t}$ its international price. $\phi_{D, i, p}$ is the elasticity of substitution of good $p$ and $b_{D, i, p}$ is the initial share of the good that is imported.

Then, once the composite good demand is determined, agents share it between importations and local demand. We assume that local and international goods are imperfect 
substitutes. More precisely, production preferences have the form of a CES function. Thus local demand $L D_{i, p, t}$ and importations $M_{i, p, t}$ of $\operatorname{good} p$ are respectively:

$$
\begin{aligned}
L D_{i, p, t} & =\left(1-b_{D, i, p}\right)^{\phi_{D, i, p}} D_{i, p, t}\left(\frac{P *_{p, t}}{\tilde{P}_{D, i, p, t}}\right)^{-\phi_{D, i, p}} \\
M_{i, p, t} & =b_{D, i, p}^{\phi_{D, i, p}} D_{i, p, t}\left(\frac{P *_{p, t}}{\tilde{P}_{D, i, p, t}}\right)^{-\phi_{D, i, p}}
\end{aligned}
$$

with $D_{i, p, t}$ the demand of the composite good.

Third, concerning the transformation industry, we assume that the share of exports and imports are fixed: $X_{i, p, t}=x S_{i, p, t}$ and $M_{i, w, t}=m D_{i, w, t}$, with $x<1$ and $m<1$. Finally, concerning timber suppliers, we assume that they face an external demand implying an export function of the type: $X_{i, w, t}=b_{S, i, w}^{\phi_{S, i, w}} D_{A, p, t}\left(\frac{\tilde{P}_{i, p, t}}{P_{*, w, t}}\right)^{-\phi_{S, i, w}}$. Where $D_{A, p, t}$ is the demand for $\mathrm{p}$ for the whole rest of the world.

We can now focus more precisely on the behavior of the three classes of agent: timber suppliers, final consumers and the transformation industry.

Timber Supply: Suppliers of good $w$ have the following supply function:

$$
S_{i, w, t}=S_{i, w, t-1}\left(\frac{P_{S, i, w, t}}{P_{S, i, w, t-1}}\right)^{\epsilon}\left(\frac{F_{i, k, t}}{F_{i, k, t-1}}\right)^{\gamma}\left(\frac{F_{i, k, t}^{\prime}}{F_{i, k, t-1}^{\prime}}\right)^{\psi}
$$

with $S_{i, w, t}$ timber supply of type $w$ at time $t$ in region $i$, and $F$ and $F^{\prime}$ are the forest stocks of type $k=l, f$. $\epsilon, \gamma$ and $\psi$ are the supply elasticities with respect to prices and stocks, respectively. Three timber supplies are distinguished: fuelwood, pulpwood and lumber. Harvest costs are not explicitly mentioned in this supply function, but are implicitly considered through price elasticities.

Those three different supplies are likely not to come from the same timber stock. Lumber stock $\left(F_{i, l, t}\right.$ and $\left.F_{i, l, t}^{\prime}\right)$ contains forest inventory which is likely to enter roundwood market. We distinguish two types of lumber stock. $F_{i, l, t}$ is the stock of timber with increasing value, while $F_{i, l, t}^{\prime}$ represents the stock of timber with decreasing value. The implicit idea is that forest owners do not have the same supply behavior with those two types of timber. Indeed, an important challenge of the model is to understand causes and patterns of forest underharvesting. In this perspective, it is crucial to distinguish the stock of timber which has achieved its optimal cutting diameter (or age). 
Stocks for pulpwood and fuelwood markets are represented by $F_{i, f, t}$ and $F_{i, f, t}^{\prime}$. Fuelwood and pulpwood are thus directly competing for the same raw materials. $F_{i, f, t}$ represents living stock, typically wood coming from coppices or thinning, and $F_{i, f, t}^{\prime}$ contains by-products, waste paper and logging residues.

Depending on the assumption made on the supplier's behavior, the patterns of timber supply (mainly elasticities) may be distinguished according to region, forest management type, property rights (private or public), timber species or accessibility.

Timber Processing Industry: As in many forestry sector models, the processing industry is represented by an input-output matrix. Transformation is made with fixed coefficient. Technologies are thus assumed constant in time, with no technical progress nor scale effects. Moreover the industry is assumed to have no market power, and only works as a transformation filter:

$$
S_{i, p, t}=\sum_{i, p} a_{p, w} D_{i, w, t}
$$

$a$ is the quantity of raw material w used to create a unit of final product p. We have six different final products p: sawnwood, plywood, pulp, fuelwood, fiber and particle board and other industrial roundwood. The unit cost of product $p$ is $c_{i, p, t}$.

Final Goods Composite Demand: Demand of timber processed goods $p$ in region $i$ at time $t$ takes the form:

$$
D_{i, p, t}=D_{i, p, t-1}\left(1+\alpha_{p} g\right)\left(\frac{\tilde{P}_{D, i, p, t}}{\tilde{P}_{D, i, p, t-1}}\right)^{\sigma_{p}}
$$

Links between $M_{i, p, t}, L D_{i, p, t}$ and $D_{i, p, t}$ are given by the Armington equation below:

$$
D_{i, p, t}=\left[\left(1-b_{D, i, p}\right) L D_{i, p, t}^{\frac{\phi_{D, i, p}-1}{\phi_{D, i, p}}}+b_{D, i, p} M_{i, p, t}^{\frac{\phi_{D, i, p}-1}{\phi_{D, i, p}}}\right]^{\frac{\phi_{D, i, p}}{\phi_{D, i, p}-1}}
$$

Base-year Data: Economic data used in building the model comes from various sources: SCEES (the French agriculture ministry service for surveys and statistic studies), FAO (Food and Agriculture Organisation UN) and French customs data. The base year chosen to initialize the model and start the projections was 2005. As our modeling is regional, some 
statistics - essentially for the demand side - are not available at the desired spatial level and was reconstituted using national observed benchmarks and some regional indicators.

National consumption was estimated as production plus imports minus exports. These values were then spatially disaggregated using regional GDP figures as indicators. Regional harvested wood and sawn wood production are available in published statistics. However data for veneer/plywood, panels and pulp was reconstituted from observed national figures and some indicators on factory capacities and number of workers. Quantities and values of foreign trade among the regions was reconstituted using national figures and regional weights furnished by French customs. Finally, inter-region trade was recovered using data on wood transport and region supply/demand balance. Prices are unit prices resulting from the surveys on final values in forest industries.

Model Parameters: Demand-side parameters come from published studies and estimates. There are important variations in these estimates because of differences in methods, countries, years covered, and model specifications. The parameters for the current model were selected so as to be consistent with recent estimates and studies for countries comparable with France (Simangunsong and Buongiorno 2001 ; Buongiorno and al. 2003 ; Kangas and Baudin 2003). Table 1 summarizes elasticities in these studies and those selected in the current model. Elasticities of substitution between domestic and imported goods in Armington equations are approximated using French data on production and imports.

Supply-function parameters of primary products are based on short-term estimates of timber supply functions. As for demand function, there are large differences exist in the published estimates of price and inventory elasticities. Buongiorno and al. (2003) use a 0.8 price elasticity for all countries. Barkaoui (2007) estimates price elasticities in France at 0.5 for broadleaved timber and 0.1 for conifer timber. In the present model, price elasticities are set at 0.5 for non-coniferous sawlogs and 0.2 for coniferous sawlogs. Finally, the elasticity of supply with regard to $F$ is set to 0.1 , and the elasticity of supply with regard to larger trees $F^{\prime}$ is set at 0.3 . 
Table 1: Comparison of Price and Income Elasticities of Consumption and Production between our Model and Literature

\begin{tabular}{|r|rr|rr|rr|}
\hline Product & \multicolumn{2}{|c|}{ Buongiorno et al. } & Kangas and Baudin & \multicolumn{2}{r|}{ Our Model } \\
\hline & price & income & price & income & price & income \\
\hline Fuelwood & & & -0.62 & -2.26 & -0.63 & -1.5 \\
\hline Sawnwood & & & -0.16 & 0.32 & & \\
\hline Coniferous sawn wood & -0.44 & 0.185 & & & -0.5 & 0.32 \\
\hline Non-coniferous sawn wood & -0.24 & 0.44 & & & -0.5 & 0.32 \\
\hline Plywood & -0.53 & 0.92 & & & & \\
\hline Veneer and plywood & & & -0.13 & 0.73 & -0.5 & 0.73 \\
\hline Particleboard & -0.15 & 1.09 & -0.24 & 1.15 & -0.4 & 1 \\
\hline Printing and writing paper & -0.25 & 1.35 & -0.15 & 1.66 & & \\
\hline Pulpwood & & & & & -0.5 & 1.2 \\
\hline
\end{tabular}

Equilibrium: At every period, the market equilibrium is given by the maximization of sum of all individual surpluses:

$$
\begin{aligned}
\max _{D_{i, p, t}, S_{i, p, t}, D_{i, w, t}, S_{i, w, t}} & =\sum_{i, p}\left(\int_{0}^{D_{i, p, t}} \tilde{P}_{D, i, p, t}\left(D_{i, p, t}\right) d D_{i, p, t}-\tilde{P}_{D, i, p, t} D_{i, p, t}\right) \\
& +\sum_{i, w}\left(P_{i, w, t} S_{i, w, t}-\int_{0}^{S_{i, w, t}} P_{i, w, t}\left(S_{i, w, t}\right) d S_{i, w, t}\right) \\
& +\sum_{i, w, p}\left(P_{i, p, t}\left(1-x-c_{i, p, t}\right) S_{i, p, t}+P_{i, p, t}^{*} x S_{i, p, t}-P_{i, w, t}(1-m) D_{i, w, t}-P_{i, w, t}^{*} m D_{i, w, t}\right) \\
& +\sum_{i, j, p}\left(\left(P_{j, p, t}-P_{i, p, t}-C_{i, j, p}\right) e_{i, j, p, t}\right) \\
& +\sum_{i, j, w}\left(\left(P_{j, w, t}-P_{i, w, t}-C_{i, j, w}\right) e_{i, j, w, t}\right)
\end{aligned}
$$

s.t.

$$
\begin{gathered}
L D_{i, p, t}+\sum_{j} e_{i, j, p, t}+x S_{i, p, t}=S_{i, p, t}+\sum_{i} e_{i, j, p, t} \\
(1-m) D_{i, w, t}+\sum_{j} e_{i, j, w, t}+X_{i, w, t}=S_{i, w, t}+\sum_{i} e_{i, j, w, t}
\end{gathered}
$$




$$
S_{i, p, t} \leq K_{t}
$$

$$
S_{i, w, t} \leq F_{i, t}+F_{i, t}^{\prime}
$$

$$
X_{i, w, t} \leq S_{i, w, t}
$$

$$
S_{i, w, t}, X_{i, w, t}, S_{i, p, t}, L D_{i, p, t}, M_{i, p, t}, e_{i, j, p, t}, e_{i, j, w, t}, P_{i, p, t}, P_{i, w, t} \geq 0
$$

Equation (10) and (11) represent material balance for products w and p. $F_{i, t}$ and $F_{i, t}^{\prime}$ refer to either $\mathrm{f}$ or $\mathrm{l}$ stock depending on which product $\mathrm{w}$ is considered. Periods are related via the growth of the timber stock (1), changes in supply (5) and changes in demand (7).

\section{Fuelwood consumption and public policy}

\subsection{Policies calibration}

We consider two sets of public policies to enhance fuelwood consumption: guaranteed provisioning and price subsidies.

In the first set of policies, the Government guarantees an additional fuelwood consumption. This can either be done directly (e.g., the public sector purchasing more fuelwood energy) or via fixed-supply arrangements whereby the Government generates the required increase in fuelwood demand from the private sector (e.g., as in the current CRE tenders ${ }^{1}$ ). The impact of such a policy on the fuelwood energy market depends on how the new plants acquire their fuelwood. There are two ways by which they can do it.

- First, the new plants can establish fixed-supply contracts whereby domestic producers guarantee that they will supply a fixed amount of fuelwood to the new plants (at market price). This is modeled by adding the amount that is contracted to the domestic supply function (5).

\footnotetext{
${ }^{1} \mathrm{CRE}$ (Energy Regulation Commission) projects consist in the implementation os biomass powerplants (Chasset, 2007; Picault, 2008).
} 
- Second, the new plants can acquire biomass directly on the domestic final goods market, an option we denote by fixed-demand contracts: they guarantee that they will purchase a fixed amount (at market price). Technically, the supplementary demand is introduced directly in the material balance equation (left hand side of equation 10) and in the consumer surplus for fuelwood.

In the second set of policies, the Government introduces two types of prices subsidies. The supply-side subsidy consists of increasing the perceived price of fuelwood suppliers; the demand-side subsidy decreases the price perceived by fuelwood consumers.

All four policies are introduced in the same year (2006), and are calibrated in such a way that fuelwood demand relative to business-as-usual increases by $8 \mathrm{Mm} 3$ in 2020. We thus test a modest scenario relative to the French Government objective: a potential increase of fuelwood biomass consumption by up to $20 \mathrm{Mm} 3$ in 2020 relative to current levels (Puech, 2009). But this conservative scenario constitutes a minimal increase over which there is a more widespread consensus, whereas the above mentioned figures are more controversial.

These four policy options are compared through: (1) their impacts on fuelwood prices, international trade, and Government budget, (2) their implications for wood inventory, and (3) their implications for the carbon balance of the forest sector.

Resource availability is actually a crucial factor determining the feasibility and the impact of such policies. We thus assess the economic impact in the case of a complete resource availability. Then, we roughly estimate a level of availability at which tensions over the resource occur, and assess those tensions implications.

\subsection{Impacts on prices and trade when the resource is widely avail- able}

\subsubsection{Effects on fuelwood prices}

Final good prices: When a consumer-side subsidy is implemented, the price perceived by consumers (e.g., the market price minus the subsidy) is lower than the price perceived by consumers in the business-as-usual (BAU). Thus, demand increases relative to BAU and the market price increases as well by 50\% in 2010 and 500\% in 2020 relative to BAU (Figure 2). 
Figure 1: Policies are calibrated so as to match the same rising path

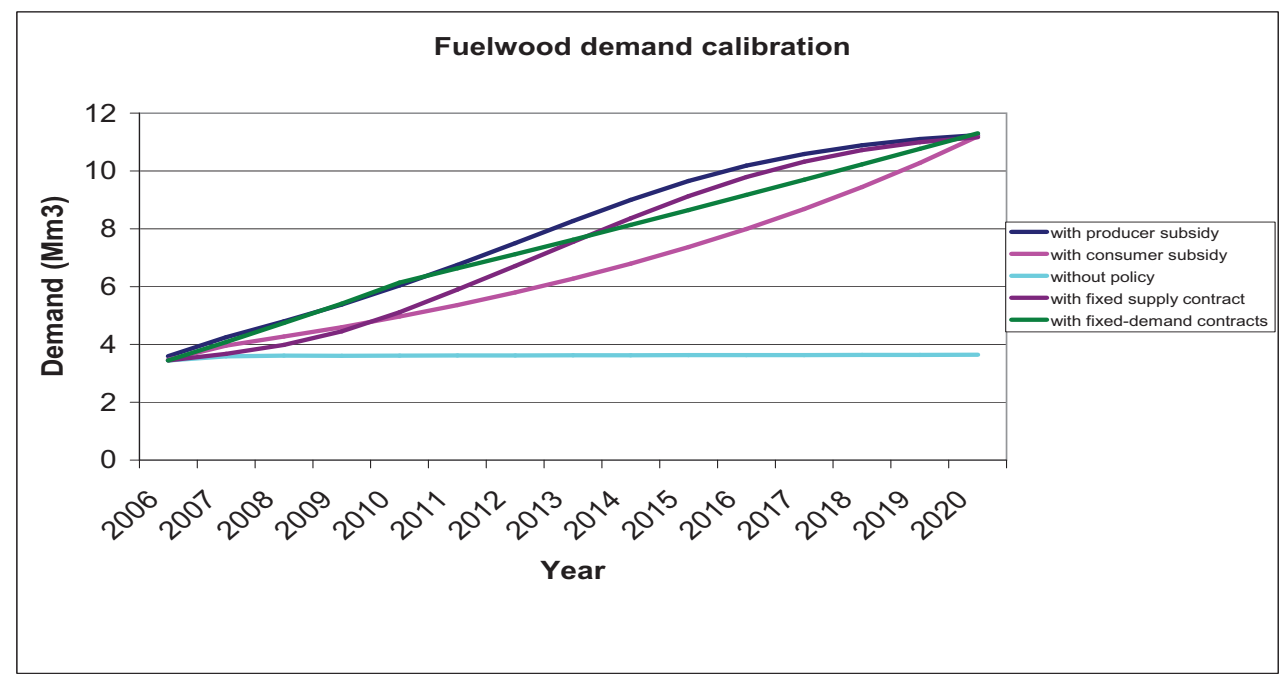

Figure 2:

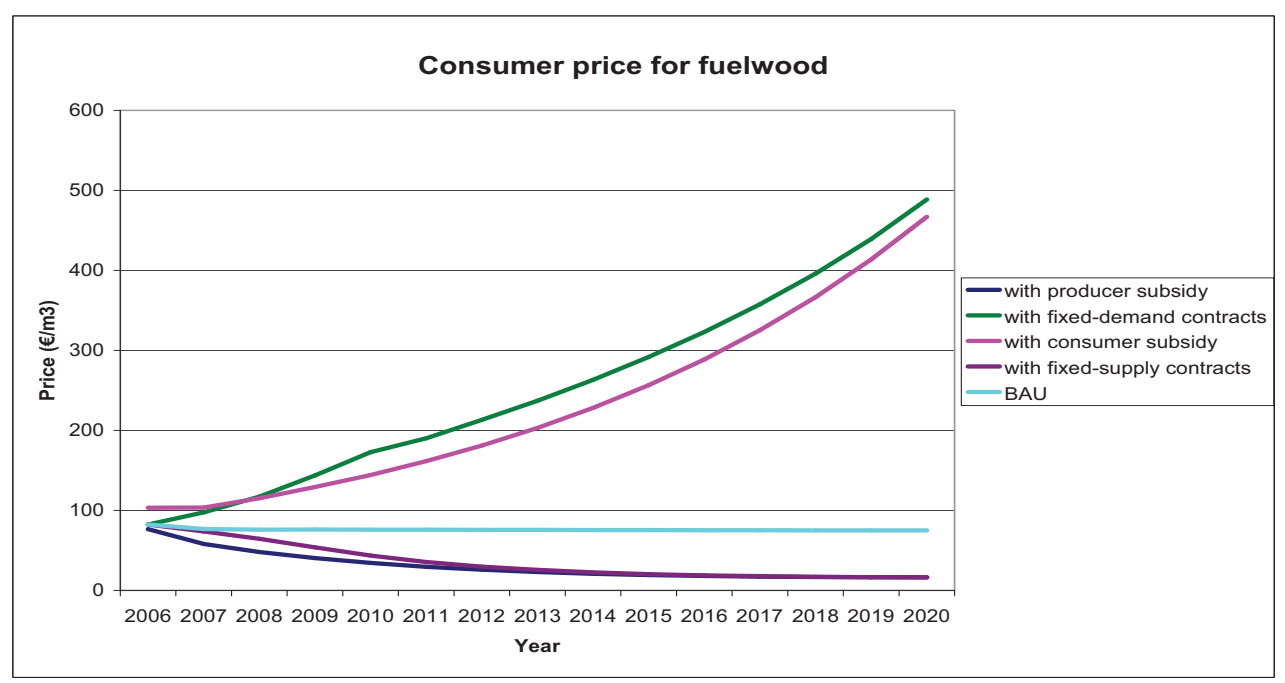


Fixed-demand contracts lead to a similar increase in consumer price of fuelwood of $77 \%$ in 2010 and of $560 \%$ in 2020 relative to BAU.

When a producer-side subsidy is implemented, fuelwood suppliers perceive a higher price and thus increase supply relative to BAU (Figure 7). This increase in primary goods supply translates into a smaller consumer price for fuelwood on the final goods market (-64\% in 2010 and $-74 \%$ in 2020 relative to BAU). ${ }^{2}$

Finally, fixed-supply contracts yield the same outcome as producer-side subsidies (Figure 2 ). This is a standard result in public economics that under perfect information and perfectly competitive markets, command-and-control policies (such as fixed-supply contracts) are equivalent to price instruments (such as producer-side subsidies).

Primary good prices: The same mechanisms apply to the producer side. Consumer-side subsidies and fixed-demand contracts increase demand for fuelwood and thus increase the price of fuelwood on the primary good market by about 300\% in 2020 relative to BAU (figure 4). Conversely, producer-side subsidies and fixed-supply contracts increase fuelwood supply by $150 \%$ in 2010 and $300 \%$ in 2020 relative to BAU and decrease the price of fuelwood on the primary good market by about $80 \%$ in 2010 and $99 \%$ in 2020 .

\subsubsection{Crowding-out effect with fixed-demand contracts}

As noted above, fixed-demand contracts increase the price of fuelwood on the final goods market (figure 2). As a result, private demand for fuelwood decreases. Thus, fixed-demand from the new plants crowds out the pre-existing private demand for fuelwood (figure 3). A policy implication is that if the objective of the Government is to reach a fixed fuelwood consumption target, then a naive implementation of fixed-demand contracts that would not take into account the crowding-out effect may undershoot the target.

\footnotetext{
${ }^{2}$ In our model, the timber processing industry has no market power. Thus the decrease in the price of biomass on the primary goods market directly translates into a decrease in the price of biomass on the final goods market.
} 
Figure 3:

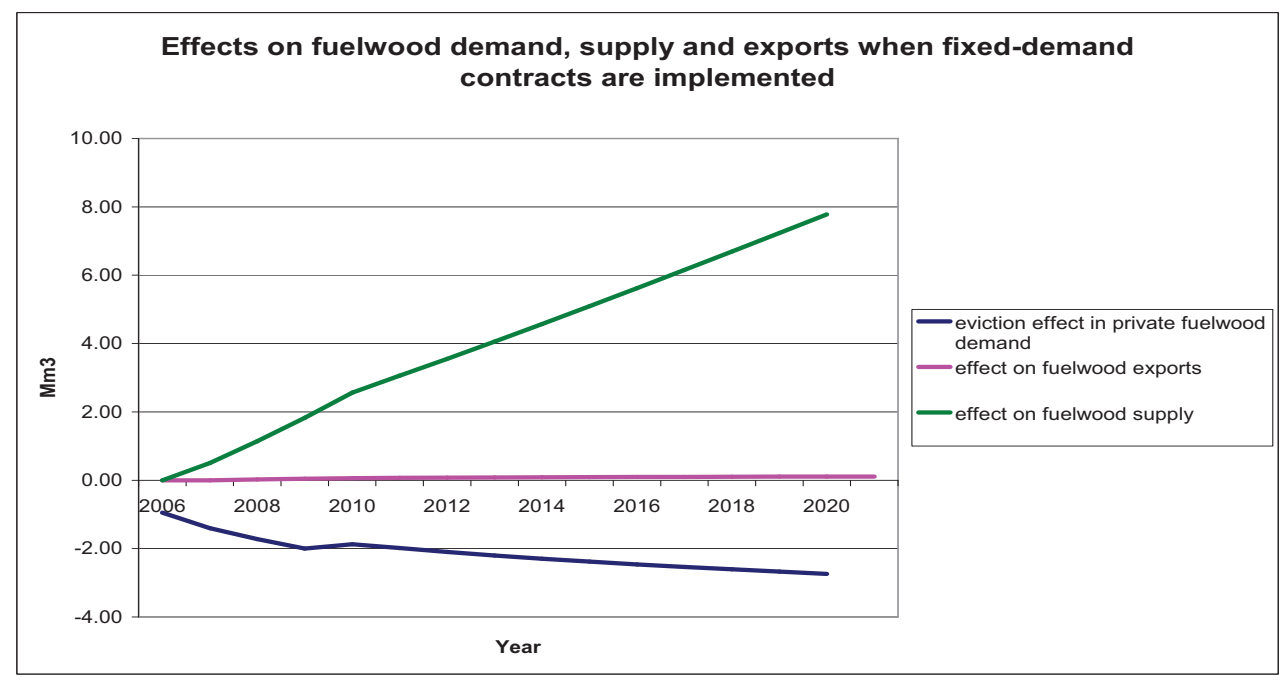

\subsubsection{Effects on trade}

Consumer-side subsidies increase the domestic prices of fuelwood both on the primary and on the final goods markets. Since international prices are constant, imports increase (figure 5) by $250 \%$ in 2010 and $530 \%$ in 2020 relative to BAU.

The effect of fixed-demand contracts on imports is a priori ambiguous. In fact, in the Armington specification, imports increase with composite demand for fuelwood and with the ratio of domestic prices to international prices (equation 4). Yet fixed-demand contracts lead both to a decrease in composite demand due to the crowding-out effect and to an increase in domestic prices relative to international prices. However, our simulations that the firstorder demand effect always dominates the second-order price effect: fixed-demand contracts always lead to a decrease in imports relative to BAU.

Finally, producer-side subsidies and fixed-supply contracts decrease domestic prices and thus increase exports or primary and final goods (figure 6). Thus, with producer-side subsidies and fixed-supply contracts, the increase in supply is larger than the increase in domestic consumption. Indeed, the increase in supply leads to a smaller domestic price, and thus to an increase in exports. A policy implication is that if the objective of the Government is to reach a fixed fuelwood consumption target, then a naive implementation of fixed-supply con- 
Figure 4:

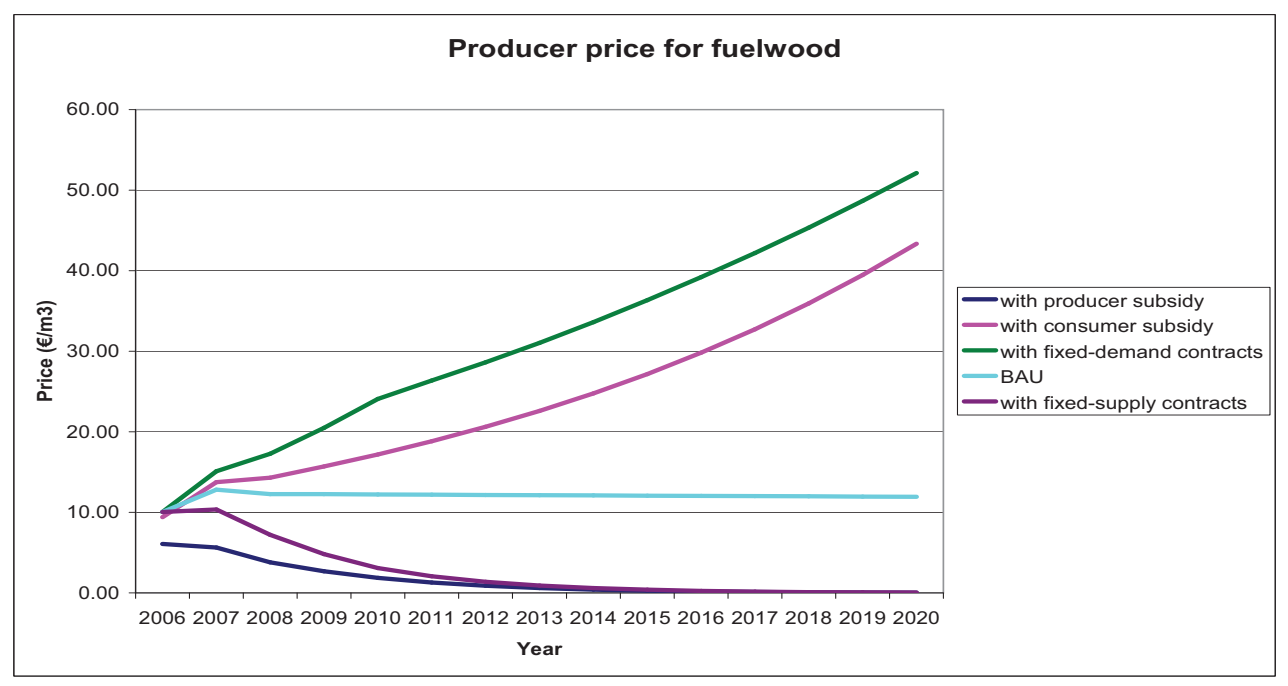

tracts that would not take into account the increase in exports may undershoot the domestic consumption target.

Overall, while consumer-side subsidies increase imports and thus increase the trade balance deficit, producer-side policies increase exports and reduce the trade balance deficit. Finally, due the the crowding-out effect, the fixed-demand policy leads to a decrease in import. Given the large trade deficit of the French forest sector (49 Mm3 for the whole French forest sector (Puech, 2009)), this is a policy-relevant result.

\subsubsection{Public budget implications}

Table 2 provides the annual budgetary costs of the four policies from 2006 to 2020. The costs of subsidies for the Government budget are easy to compute: subsidy level times demand (or supply). The costs of fixed-demand (supply) contracts consist of final goods (primary goods) market prices times the additional amount of fuelwood demanded (supplied). In other words, we assume here that the Government purchases the additional amount of fuelwood.

The costs of subsidies and the costs of guaranteed provisioning contracts for the Government are difficult to compare. While subsidies consist of paying private suppliers or consumers, guaranteed provisioning contracts consist of a public purchase of fuelwood. As 
Figure 5:

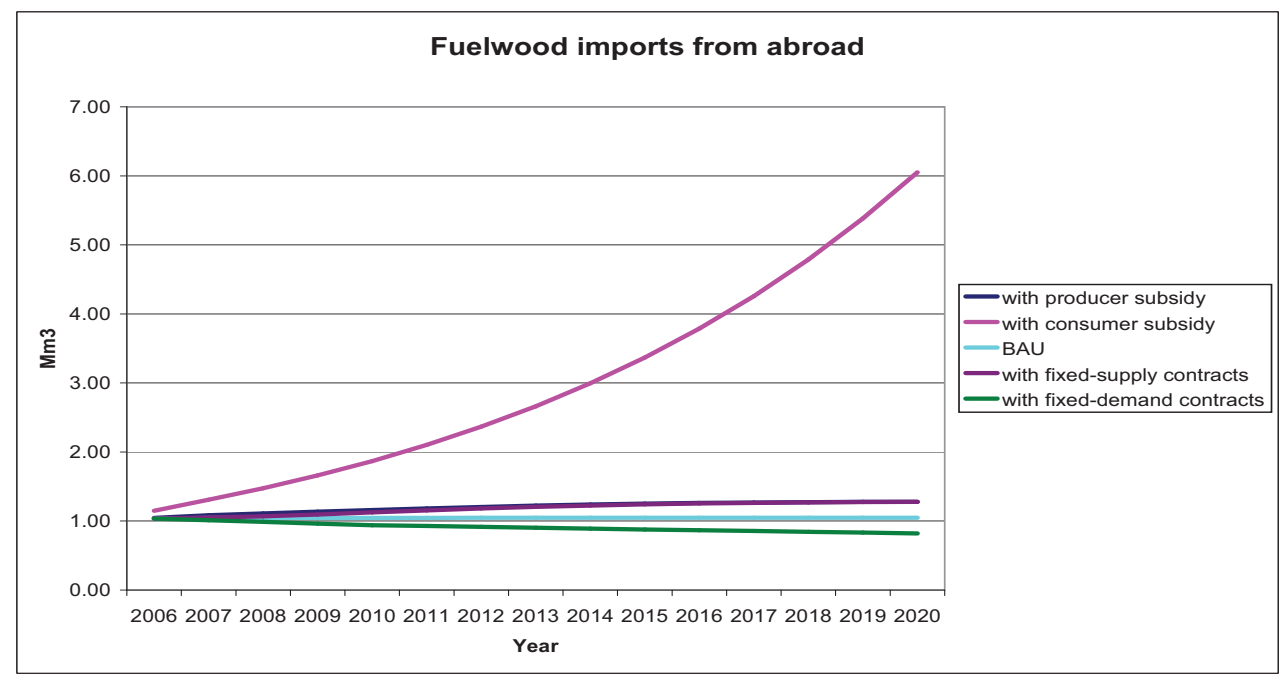

Figure 6:

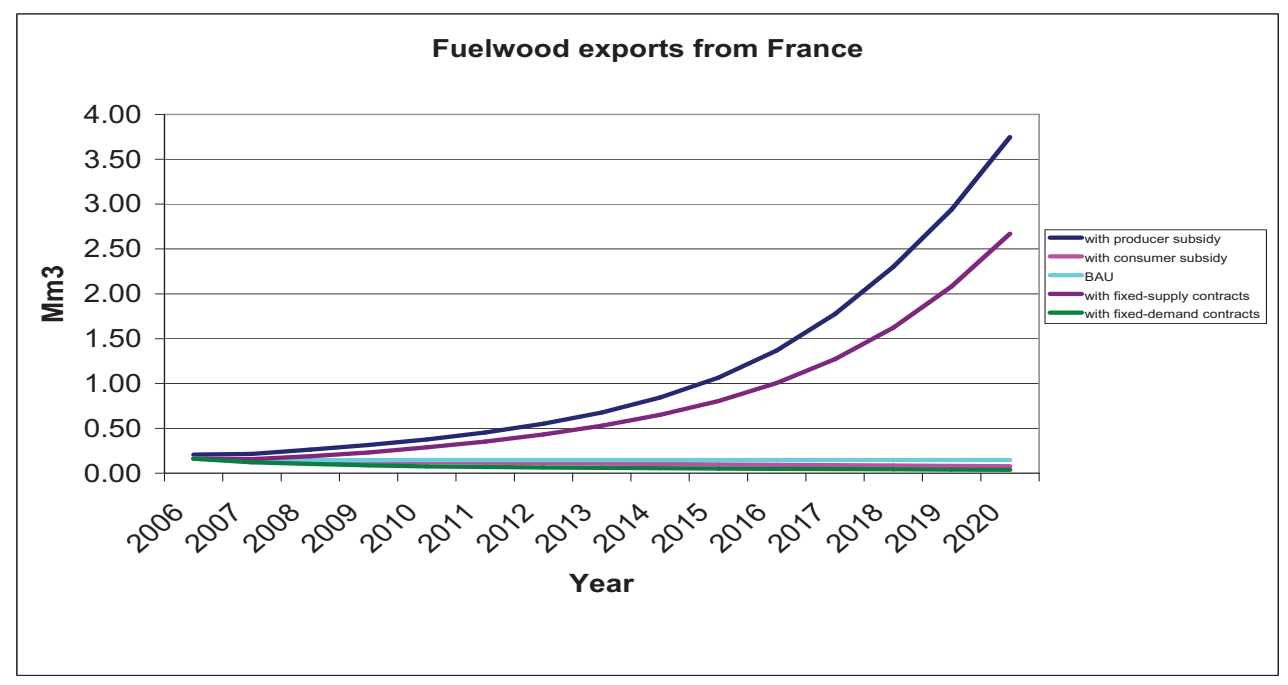


Figure 7:

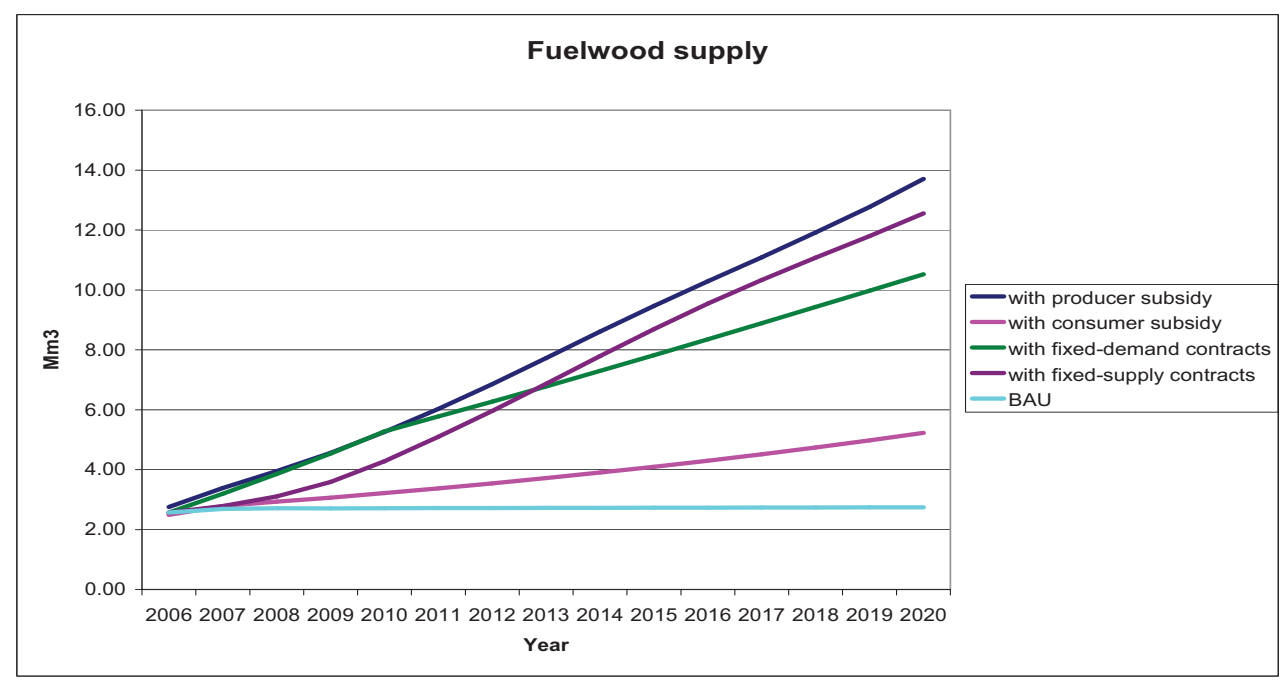

Table 2: The costs of subsidies and the costs of guaranteed provisioning contracts are difficult to compare

\begin{tabular}{|c|c|c|c|c|}
\hline Year & 2007 & 2010 & 2015 & 2020 \\
\hline Producer subsidy $(€)$ & 12.6 & 160 & 754 & 1794 \\
\hline Consumer subsidy $(€)$ & 17 & 157 & 879 & 3403 \\
\hline Fixed-demand contracts $(€)$ & 185 & 760 & 2159 & 5081 \\
\hline Fixed-supply contracts $(€)$ & 7.2 & 5 & 1.35 & 0.3 \\
\hline
\end{tabular}

a result, the Governement can decrease its consumption from other energy sources. Table 2 does not take into account this substitution effect.

\subsubsection{Tensions over forest resources}

As mentioned before, we assess here the impact of a quite optimistic scenario on the forest sector. First, we have considered an increase in fuelwood consumption of 8 Mm3 in 2020 relative to 2006 level, while currently discussed objectives mention a $+21 \mathrm{Mm} 3$ increase in fuelwood consumption in 2020 (Puech, 2009). Second, we assume a large availability of forest resources to harvest. 
It follows that the policy objective can be easily reached in this context. Moreover, the increase in fuelwood consumption is over-compensated by natural increment. Since there is no tension over the resource, the increase in fuelwood consumption does not yield any eviction effect on the pulpwood market.

\subsection{Tensions when forest resources are less available}

The available stock $F_{f, i, 2006}$ for fuelwood or pulpwood in each region for 2006 is only a fraction of the gross stock of standing biomass. First, some areas are not harvestable by law (biological reserves, etc.). Second, some forest owners - particularly small-scale forest owners, who make up $30 \%$ of total forest land - appear not to respond to the economic environment, in particular to the price of timber, in their forest management. This may be due to lack of information, high valuation of the environmental, aesthetic or bequest values of their forests, or low value of their forest relative to their other revenues (Amacher, 2003; Binkley, 1981).

Starting from a complete availability of forest stock to harvest, we progressively restrict this level of availability ( $r s)$ and check the point at which tensions start to appear. $r s$ is the share of the 2006 total forest stock available to harvest. We distinguished two kinds of tensions. First, tensions over the resource describe the point at which harvesting exceeds natural increment. Tensions over the resource thus start when harvestable forest stock starts to decrease. Second, economic tensions can be represented by the pulpwood price. Indeed, pulpwood is directly in competition with fuelwood since both products are extracted from the same forest stock. Moreover, in contrast with fuelwood prices, pulpwood prices are not directly related to the public policy.

Tensions over harvestable resources appears in BAU when availability $(r s)$ on the initial stock is below $50 \%$ of the forest stock, which represents an initial stock for pulpwood and fuelwood of $250 \mathrm{Mm}^{3}$. Below this level, harvested volumes exceed natural increment (see figure 8).

Pulpwood price does not significantly increase above $r s=0.25$, which gives the intuition that there is no important economic tension (figure 9). Below this threshold, pulpwood price 
Figure 8: Harvestable pulpwood and fuelwood stock dynamics

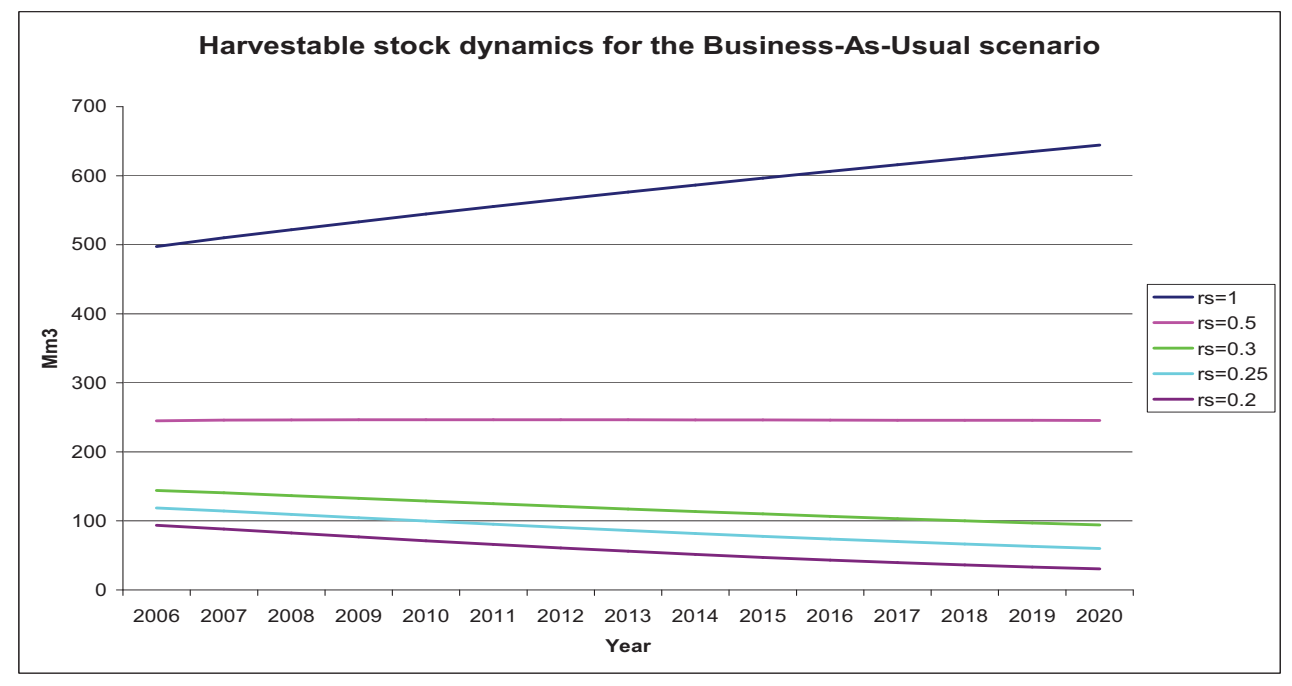

indeed increases. This gives the intuition that our economic tension indicator only reacts once resource tensions are already quite important.

\subsection{Effects of policies on carbon stock and flows}

As noticed in the introduction, one of the overarching goal of increasing biomass energy consumption is to reduce greenhouse gases emissions. However, this increase in consumption has two different impacts on the national carbon balance. First, as long as biomass is replanted in a sustainable manner, fuelwood consumption is virtually carbon-neutral. Replacing fossilfuel by biomass energy thus creates a positive substitution effect. Second, however, increase in biomass consumption may lead to a decrease in total standing stock, and thus on the total amount of carbon sequestered in national forests.

Our policies are calibrated so that they generate the same increase in fuelwood consumption. It follows naturally that they imply the same substitution effect. Conversely the different policies leads to different scenarii concerning timber harvesting. Thus they imply different impact on the carbon stock.

As noticed above, a consumer-side subsidy is more resource preserving than producer-side policies. Indeed, with consumer-side subsidy, the increase in fuelwood demand is compen- 
Figure 9:

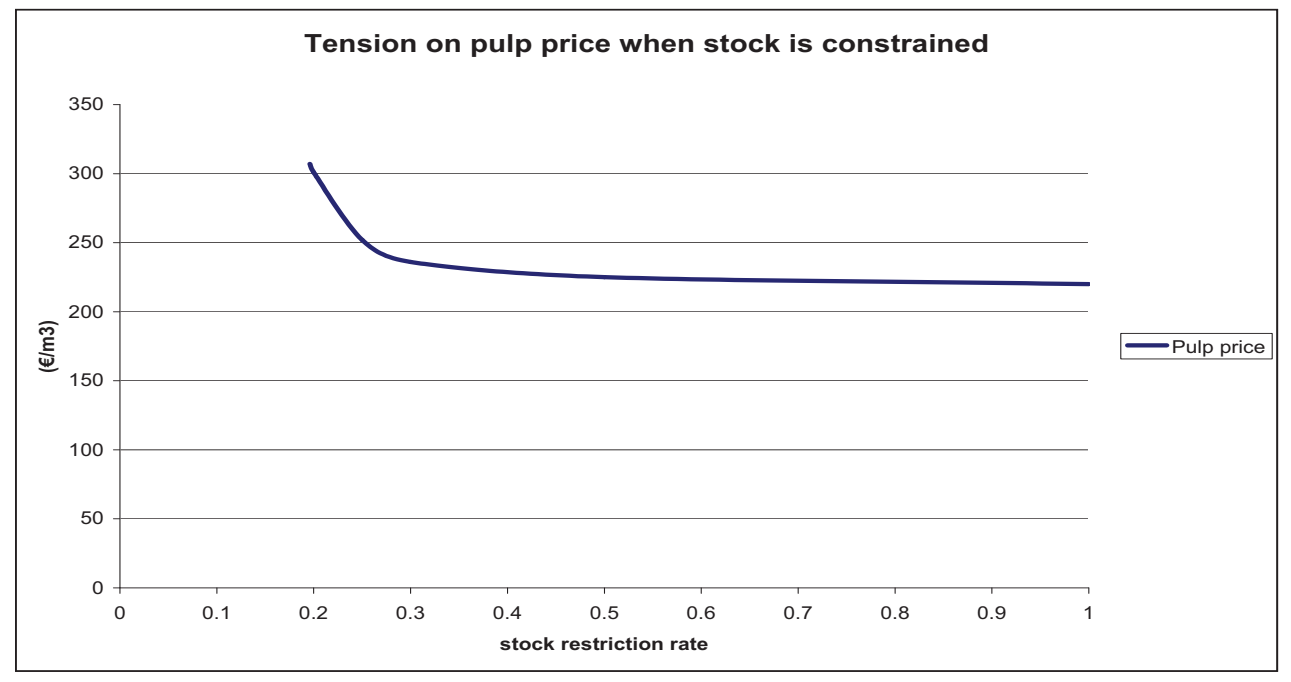

sated by a large share in imports. With a producer-side policy, the whole increase in fuelwood consumption is removed from the domestic forest stock. Moreover, exports increase. The total carbon stock thus widely decrease. Results are even different with fixed-demand contracts: in this case, supplementary demand is supplied by domestic producers but exports do not increase, that leads to an intermediate situation in comparison with consumer subsidy and producer-side policies. Overall, the decrease in stock is 4.8 times and 1.3 time larger with producer subsidy than with consumer subsidy and fixed-demand contracts respectively

Overall, it is important to note that the figures are quite sensitive to several model parameters. Indeed, larger waste in fuelwood transformation, elasticities of substitution between domestic and foreign products, and carbon accounting methods imply important variations of our carbon inventory.

\section{Conclusion}

It has often been suggested that a policy increasing fuelwood demand would affect sectors in competition with fuelwood, such as pulpwood. Our goal was thus to understand the potential 
impacts of a rise in fuelwood consumption on both the fuelwood sector and the pulpwood sector. We made it possible by implementing a new French forest sector model that takes into account French particularities. We then considered four different policy options and diverse assumptions about timber availability.

First, our results clearly show that, when implemented, the two types of subsidies lead to different trend in supply, exports and imports. Indeed, comparing supplier-side and consumer-side policies implies a trade off between the trade balance and resource harvesting. Thus, a consumer-side subsidy appears to have a smaller negative impact on the carbon stock than a producer-side subsidy, since it provides a part of the additional fuelwood demand with imports. Second, fixed-demand contracts led to an eviction effect in private fuelwood demand that does not appear with both consumer subsidy and producer subsidy. Finally, economic and resource tensions essentially depends on timber availability. Resource tensions appear at larger degree of timber availability than economic tensions. This gives the intuition that economic indicators may be poor indicators of ecological and resource tensions.

Being a first approximation, this starting point is still highly perfectible and points out future improvements. On the biological part, it is essential to strengthen the stock dynamics, by getting a more precise and accurate idea of timber growth. Moreover carbon accounting is quite sensitive to accounting methods and thus needs to be precisely and cautiously defined. In this context, a research agenda has been set with a French Forest Inventory (IFN) in order to get a more accurate estimation of timber dynamics.

On the economic side, implementing imperfect substitution concerning timber supply and the transformation sector using Armington theory (1969) seems a natural extension. Second, it is important to refine suppliers behavior in order to better describe the patterns that may lead to under-harvesting of the forest resources. In order to better understand longterm patterns, the land-use choice of land-owners has to be considered. Indeed, we consider here that forest management and replanting practices are constant in time. However, it is likely that those patterns respond to long-term price variation. Finally, we consider here that fuelwood consumption is as flexible as any good. However, it is likely that energy consumption presents some inertia, which would have to be considered to get a more precise idea of long-term evolution. 


\section{References}

ADEME (2007). Programme national bois énergie 2000-2006. Rapport d'activité 2000-2005.

Amacher, G., Conway, C., and Sullivan, J. (2003). Econometric analysis of forest landowners: is there anything left to study? Journal of Forest Economics, 9(2):137-164.

Armington, P. S. (1969). A theory of demand for products distinguished by place of production? IMF Staff Papers, 16(1):159-176.

Ballu, J. (2007). Pour mobiliser la ressource de la forêt française. Technical report, Ministère de l'agriculture et de la pêche.

Barkaoui, A. (2007). An econometric supply/demand modelling of domestic timber in

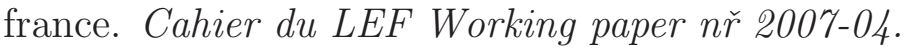

Binkley, C. (1981). Timber supply from nonindustrial forests: a microeconomic analysis of landowner behavior. Yale University Press, New Haven, CT.

Brannlund, R., Johansson, P.-O., and Lofgren, K. (1985). An economic analysis of aggregates awtimber and pulpwood supply in sweden. Forest Science, 31:595-606.

Buongiorno, J., Zhu, S., Zhang, D., and Tomberlin, D. (2003). The Global Forest Products Model: Structure, Estimation, and Applications. Academic Press.

Chasset, C. (2007). Perspectives de mobilisation de bois énergie à la société forestière de la caisse des dépots. Mémoire de fin d'étude, Nancy, ENGREF.

ENGREF (1984). Tables de production pour les forêts françaises. Ecole Nationale du Génie Rural des Eaux et des Forêts, 160 p.

Kangas, K. and Baudin, A. (2003). Modelling and projections of forest products demand, supply and trade in europe. United Nations, Geneva. Geneva Timber and Forest Discussion Paper 30. ECE/TIM/DP/30.

Kuuluvainen, J. and Salo, J. (1991). Timber supply cycle of non-industrial private forest owners: An empirical analysis of the finnish case. Forest Science, 37 (4):1011-1029. 
Newman, D. (1987). An econometric analysis of the southern softwood stumpage market: 1950-1980. Forest Science., 33:932-945.

Picault, L. (2008). Les reboisements à vocation de production de biomasse: enjeux, contraintes et perspectives pour les pépinières naudet. Mémoire de fin d'étude INH.

Puech, J. (2009). Mise en valeur de la forêt française et développement de la filière bois. Technical report.

Roy, C. (2006). Plan biocombustibles (plan directeur pour la valorisation de la biomasse). Coordinateur interministériel pour la valorisation de la biomasse.

Samuelson, P. A. (1952). Spatial price equilibrium and linear programming. The American Economic Review, 42(3):283-303. 